\title{
SARS-CoV-2 infections in people with primary ciliary dyskinesia: neither frequent, nor particularly severe
}

\begin{abstract}
To the Editor:
Copyright (CThe authors 2021.

This version is distributed under the terms of the Creative Commons Attribution Non-Commercial Licence 4.0. For commercial reproduction rights and permissions contact permissions@ersnet.org

Received: 17 Dec 2020 Accepted: 24 March 2021

\section{๑๑థ@}

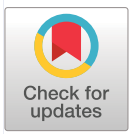

The coronavirus disease 2019 (COVID-19) pandemic caused by severe acute respiratory syndrome coronavirus 2 (SARS-CoV-2) had by March 2021 infected $\geqslant 115$ million people worldwide and caused $>2.5$ million deaths. People with pre-existing chronic health conditions are reportedly at high risk of catching the disease and of having a severe disease course [1-4]. Primary ciliary dyskinesia (PCD) is a multisystem, genetic disease which affects approximately 1 in 10000 people and leads to chronic upper and lower airway disease, laterality defects, including congenital heart disease, and other health problems [5-8]. In March 2020, PCD patient support groups contacted the paediatric respiratory research group at the University of Bern (Bern, Switzerland) with the wish to set up a study that generates evidence on the risk and evolution of COVID-19 in people with PCD. This led to the launch of COVID-PCD, a longitudinal online survey of health, shielding behaviours and quality of life of people with PCD during the pandemic. COVID-PCD is a participatory study that collects data in real-time directly from people with PCD using online questionnaires. This article provides the first data on risk and severity of SARS-CoV-2 infections among study participants for the time period between 30 May 2020 and 5 March 2021.

A detailed description of the methods has been published [9]. In short, COVID-PCD is an international study advertised through PCD support groups and is open to people of any age with a confirmed or suspected diagnosis of PCD who can complete questionnaires in English, German, Spanish, Italian or French. The study has been approved by the cantonal ethics committee of Bern (study ID 2020-00830), is registered with clinicaltrials.gov (NCT04602481) and is anonymous. PCD support groups from the United Kingdom (UK), United States of America (USA), Switzerland and Australia helped to develop patient information and questionnaires, and helped to pilot the study before the recruitment started. Since 30 May 2020, participants have been able to register and consent via the study website (www.covid19pcd.ispm.ch) and then receive e-mail links to online questionnaires. A baseline questionnaire collects demographic data, information about the PCD diagnosis and severity using the standardised FOLLOW-PCD questionnaires [10], and information on SARS-CoV-2 infections that had occurred prior to study entry. 1 week after completing the baseline questionnaire, and at weekly intervals thereafter, participants receive short follow-up questionnaires about current symptoms, shielding behaviour and incident SARS-CoV-2 infections. Questions asking about incident SARS-CoV-2 infections refer to the time passed since completing the last follow-up questionnaire, ensuring that all incident SARS-CoV-2 infections are reported, even if a participant fails to complete a weekly questionnaire. Parents complete questionnaires for children aged $<13$ years.

We described the number and proportion of study participants who received a test for SARS-CoV-2 at any time, summing up antigen tests and antibody tests. We then calculated the proportion of people with a confirmed SARS-CoV-2 infection by dividing the number of those with a positive PCR or antibody test at any time (prior to study entry, or during the observation period) by the study population. Participants were asked how seriously ill they had been, with answers categorised as no symptoms, mild symptoms (e.g. mild fever and/or cough) or moderate symptoms (e.g. high fever, cough, headache). In addition, we asked participants if they had been treated in the hospital due to COVID-19, and if yes, for how long. We calculated the incidence rate of SARS-CoV-2 infections in those who had been disease-free at study entry (the population at risk). We defined an incident case as a positive SARS-CoV-2 test result reported

\section{Shareable abstract (@ERSpublications)}

In this longitudinal study of people with PCD followed weekly via online questionnaires, the incidence rate of COVID-19 and the proportion of participants infected were low, and the observed severity mostly mild https://bit.ly/3frKICr

Cite this article as: Pedersen ESL, Goutaki M, Harris AL, et al. SARS-CoV-2 infections in people with primary ciliary dyskinesia: neither frequent, nor particularly severe. Eur Respir J 2021; 58: 2004548 [DOI: 10.1183/13993003.04548-2020].
\end{abstract}


$\geqslant 14$ days after study entry. This criterion was set to minimise the risk of selection bias from people registering because of typical symptoms or contact with a case. We defined person-time at risk as time between completing the baseline questionnaire and the latest follow-up among those without SARS-CoV-2 at baseline. Participants who reported a positive test for SARS-CoV-2 remained in the study, allowing the detection of possible re-infections. For each observation week, we calculated the proportion of study participants who reported behaviours related to shielding, such as not leaving the house, visiting grocery stores, going to school or work and using public transport, and then averaged these proportions over all observation weeks.

By 5 March 2021, 640 persons with PCD had registered in COVID-PCD (median age 27 years, range 185 years). 234 (37\%) were aged <20 years, 299 (47\%) were aged 20-49 years and 107 (16\%) were aged $>49$ years (table 1). 61\% were female. The longest time a participant was followed-up was 37 weeks (median 12 weeks, interquartile range 4-27 weeks); 70 (11\%) participants only completed the baseline questionnaire. Five people left the study (one died, not due to COVID-19, and four did not give a reason). 308 (48\%) participants had never been tested for SARS-CoV-2, 173 (27\%) had been tested once and 159 (25\%) twice or more. 24 participants reported a positive SARS-CoV-2 test either at study entry or during the observation period, corresponding to $3.8 \%$ of the study population (95\% CI $2.4-5.5 \%$ ). Eight cases occurred in those aged $<20$ years, 10 in those aged $20-49$ years and six in those aged $\geqslant 50$ years. Overall, reported severity in the 24 cases was mild, with five reporting no symptoms, 12 reporting mild symptoms, four reporting moderate symptoms without hospitalisation and three persons reporting hospitalisation (one with mild symptoms, hospitalised for 9 days; two with moderate symptoms, hospitalised for 7 and 9 days). None needed intensive care or artificial ventilation, and none died from COVID-19. 16 of the 24 infections were reported at the time of registration into the study, and eight incident infections were observed during follow-up. The total follow-up time was 90999 days (249 person-years). This resulted in an incidence rate of 3.2 per 100 person-years (95\% CI 1.6-6.4 per 100 person-years), meaning that if 100 participants had been observed for a year, three would have caught COVID-19 during this year. Incidence was highest in

TABLE 1 Severe acute respiratory syndrome coronavirus 2 (SARS-CoV-2) infections and shielding behaviour in people with primary ciliary dyskinesia (PCD), based on longitudinal data from the COVID-PCD study

\begin{tabular}{|c|c|c|c|c|}
\hline & Total & $\begin{array}{l}\text { Children } \\
\text { (0-19 years) }\end{array}$ & $\begin{array}{l}\text { Adults } \\
\text { (20-49 years) }\end{array}$ & $\begin{array}{l}\text { Older adults } \\
\text { ( }>49 \text { years) }\end{array}$ \\
\hline Study participants & 640 & 234 & 299 & 107 \\
\hline Female & $389(61)$ & $112(48)$ & $207(69)$ & $70(66)$ \\
\hline \multicolumn{5}{|l|}{ Tested for SARS-CoV-2 } \\
\hline Never & $308(48)$ & $118(50)$ & $147(49)$ & $43(40)$ \\
\hline $\begin{array}{l}\text { Confirmed SARS-CoV- } 2 \text { infections (positive PCR or antibody test at any } \\
\text { time during study period) } n(\%, 95 \% \mathrm{Cl})\end{array}$ & $24(3.8,2.4-5.5)$ & $8(3.4,1.5-6.6)$ & $10(3.3,1.6-6.1)$ & $6(6.0,2.1-11.8)$ \\
\hline No symptoms & $5(21)$ & & 2 & 0 \\
\hline Mild symptoms, not hospitalised ${ }^{\#}$ & $12(50)$ & 3 & 6 & 3 \\
\hline Moderate symptoms, not hospitalised ${ }^{\natural}$ & $4(17)$ & 1 & 1 & 2 \\
\hline Hospitalised $^{+}$ & $3(12)$ & 1 & 1 & 1 \\
\hline \multicolumn{5}{|l|}{$\begin{array}{l}\text { Shielding behaviour during the past } 7 \text { days during } 37 \text { weeks of } \\
\text { follow-up }{ }^{\S} \%\end{array}$} \\
\hline Did not leave the house & $10(3-17)$ & $10(1-20)$ & $9(3-19)$ & $10(3-19)$ \\
\hline Went for grocery shopping & $38(22-46)$ & $18(6-26)$ & $51(24-66)$ & $42(22-60)$ \\
\hline Went to workplace/school ${ }^{f}$ & $37(16-57)$ & $44(8-75)$ & $31(6-49)$ & $34(19-46)$ \\
\hline Used public transportation & $13(5-18)$ & $13(0-21)$ & $13(8-22)$ & $13(5-21)$ \\
\hline \multicolumn{5}{|c|}{$\begin{array}{l}\text { Data are presented as } \mathrm{n}, \mathrm{n}(\%) \text { or mean (range), unless otherwise stated. ICU: intensive care unit. \#: referred to in the questionnaire as "mild fever } \\
\text { or cough"; } \text { ": referred to in the questionnaire as "high fever, cough, headache, etc."; }{ }^{+}: \mathrm{n}=2 \text { moderate symptoms ( } \mathrm{n}=1 \text { hospitalised for } 7 \text { days, } \mathrm{n}=1 \\
\text { hospitalised for } 9 \text { days), } \mathrm{n}=1 \text { mild symptoms (hospitalised for } 9 \text { days); }{ }^{\S}: \text { we calculated the proportion of people in each week, and then averaged } \\
\text { this proportion over the } 32 \text { weeks of the observation period; }{ }^{f}: \text { among those who go to school or work. }\end{array}$} \\
\hline
\end{tabular}


adults aged $\geqslant 50$ years, with 6.0 per 100 person-years (95\% CI 2.2-17.9 per 100 person-years) and only one incident case was observed in adults aged 20-49 years. During the follow-up period, $10 \%$ of study participants on average reported not to have left their house during the past 7 days (range 3-17\%). 38\% had left the house for grocery shopping in the past week (range 22-46\%), 37\% had been to school or workplace (range 16-57\%) and 13\% had used public transport (range 5-18\%). These proportions varied from week to week and between regions.

In summary, this international longitudinal study of 640 people with PCD found that only 3.8\% of the study population had a SARS-CoV-2 infection confirmed by a specific test. This was lower compared to the overall UK population, for example, with a cumulative confirmed number of cases of $6.3 \%$, Italy $5.0 \%$ and the USA 8.8\%, but similar to Germany with 3\% (5 March 2021) [11]. We observed one confirmed case in children aged $0-9$ years $(0.8 \%$ of 122 children aged $0-9$ years, data not shown) which compares well with national data from Switzerland, where $0.8 \%$ of children aged $0-9$ years had a laboratory-confirmed SARS-CoV-2 infection (3 March 2021) [12]. An explanation for this may be that children are more often asymptomatic and SARS-CoV-2 infections therefore stay undetected [13]. We observed fewer cases in participants aged 20-49 years (10 (3.3\%) out of 299) than in the general Swiss population (7.9\%) [12]. This suggests that adults with PCD are more careful in shielding themselves because they consider themselves to be high-risk. Overall, the severity of cases seems to be milder than that found for cystic fibrosis. For PCD, we found that three (12\%) out of 24 were hospitalised due to COVID-19 and no-one was admitted to the intensive care unit (ICU). A French study of 7500 cystic fibrosis patients from 47 clinics found that 31 had tested positive for SARS-CoV-2 by June 2020 [14]. Among the 31, 61\% had been hospitalised and 13\% (four out of 31) were in the ICU [14]. The difference between the two studies might partly be explained by a higher degree of detection bias in the hospital-based French study, where mild infections not resulting in hospitalisations might have been missed by the physicians. This bias is less relevant, albeit not absent, for our participatory study, with patients themselves reporting weekly on their health. When we compare severity of infections with data from the general population, more people were hospitalised in our study (three out of 24 cases; $12 \%$, 95\% CI 2.7-32.4\%) compared to data from Switzerland where 23869 of the 554808 confirmed cases (4.3\%, 95\% CI 4.25-4.36\%) were hospitalised. However, the severity of COVID-19 is strongly associated with age; most hospitalisations occurred in people aged $\geqslant 70$ years. The age distribution in our study differs from that of the general Swiss population; the proportion of people aged $\geqslant 49$ years was $16 \%$ in our study, but $40 \%$ in the general Swiss population. Only nine participants in our study were aged $\geqslant 70$ years. Therefore, we can not compare severity. The low numbers of cases and hospitalisations for COVID-19 are reassuring, but also a limitation of this study, because it is difficult to draw conclusions about severity based on only 24 cases. Additionally, in our study, only 52\% had been tested for SARS-CoV-2 and it is possible that some participants had an undetected infection. This is also the case in the general population, and we assume that if a SARS-CoV-2 infection was missed, that participant had mild symptoms. Another limitation is the anonymous participation, which did not allow validation of hospitalisations and deaths through record linkage. However, the anonymous online design has enabled the development of the largest international cohort study collecting data directly from people with PCD.

The reassuring results of this study are probably partly explained by the careful shielding behaviour of our study participants; on average, $10 \%$ had not left their house in the past week and less than half had gone to school or work. But even so, the study suggests that with careful personal protection, people with PCD do not seem to have an increased risk of infection with SARS-COV-2, nor an especially severe disease course.

Eva S.L. Pedersen $\oplus^{1}$, Myrofora Goutaki $\oplus^{1,2}$, Amanda L. Harris $\oplus^{3}$, Lucy Dixon ${ }^{4}$, Michele Manion ${ }^{5}$, Bernhard Rindlisbacher ${ }^{6}$, COVID-PCD patient advisory group ${ }^{8}$, Jane S. Lucas $\oplus^{3,7}$ and

Claudia E. Kuehni $\oplus^{1,2}$

${ }^{1}$ Institute of Social and Preventive Medicine, University of Bern, Bern, Switzerland. ${ }^{2}$ Paediatric Respiratory Medicine, Children's University Hospital of Bern, University of Bern, Bern, Switzerland. ${ }^{3}$ Primary Ciliary Dyskinesia Centre, NIHR Biomedical Research Centre, University Hospital Southampton NHS Foundation Trust, Southampton, UK. ${ }^{4}$ PCD Family Support Group, London, UK. ${ }^{5}$ PCD Foundation, Minneapolis, MN, USA. ${ }^{6}$ Selbsthilfegruppe Primäre Ciliäre Dyskinesie, Steffisburg, Switzerland. ${ }^{7}$ University of Southampton Faculty of Medicine, School of Clinical and Experimental Medicine, Southampton, UK. ${ }^{8}$ The members of the COVID-PCD patient advisory group are listed in the acknowledgements section. 
Acknowledgements: We thank all participants and their families, and we thank the PCD support groups and physicians who have advertised the study. We thank our collaborators who helped set up the COVID-PCD study: Eugenie Collaud, Rebeca Mozun, Cristina Ardura, Yin Ting Lam, Christina Mallet, Helena Koppe and Dominique Rubi (University of Bern, Bern, Switzerland). We thank Francesca Santamaria, Federica Annunziata and Vincenzo Miranda (Federico II University, Naples, Italy), for translating the study questionnaires to Italian.

COVID-PCD patient advisory group (in alphabetical order): Sara Bellu, Associazione Italiana Discinesia Ciliare Primaria Sindrome di Kartagener Onlus Italy; Fiona Copeland, PCD Family Support Group UK, UK; Katie Dexter, PCD Family Support Group UK; Lucy Dixon, PCD Family Support Group UK; Susanne Grieder, Selbsthilfegruppe Primäre Ciliäre Dyskinesie, Switzerland; Catherine Kruljac, PCD Australia Primary Ciliary Dyskinesia, Australia; Michelle Manion, PCD Foundation, USA; Bernhard Rindlisbacher, Selbsthilfegruppe Primäre Ciliäre Dyskinesie, Switzerland; Hansruedi Silberschmidt, Verein Kartagener Syndrom und Primäre Ciliäre Dyskinesie, Germany.

Conflict of interest: None declared.

Support statement: This research was mainly funded by the Swiss National Foundation (SNF 320030B_192804/1), and also received support from the PCD Foundation, United States; the Verein Kartagener Syndrom und Primäre Ciliäre Dyskinesie, Germany; the PCD Family Support Group, UK; and PCD Australia, Australia. Study authors participate in the BEAT-PCD clinical research collaboration, supported by the European Respiratory Society. Funding information for this article has been deposited with the Crossref Funder Registry.

\section{References}

1 Noor FM, Islam MM. Prevalence and associated risk factors of mortality among COVID-19 patients: a meta-analysis. J Community Health 2020; 45: 1270-1282.

2 Chen N, Zhou M, Dong X, et al. Epidemiological and clinical characteristics of 99 cases of 2019 novel coronavirus pneumonia in Wuhan, China: a descriptive study. Lancet 2020; 395: 507-513.

3 Zhou F, Yu T, Du R, et al. Clinical course and risk factors for mortality of adult inpatients with COVID-19 in Wuhan, China: a retrospective cohort study. Lancet 2020; 395: 1054-1062.

4 Wong AW, Shah AS, Johnston JC, et al. Patient-reported outcome measures after COVID-19: a prospective cohort study. Eur Respir J 2020; 56: 2003276.

5 Kuehni CE, Frischer T, Strippoli MP, et al. Factors influencing age at diagnosis of primary ciliary dyskinesia in European children. Eur Respir J 2010; 36: 1248-1258.

6 Shapiro AJ, Davis SD, Ferkol T, et al. Laterality defects other than situs inversus totalis in primary ciliary dyskinesia: insights into situs ambiguus and heterotaxy. Chest 2014; 146: 1176-1186.

7 Goutaki M, Meier AB, Halbeisen FS, et al. Clinical manifestations in primary ciliary dyskinesia: systematic review and meta-analysis. Eur Respir J 2016; 48: 1081-1095.

8 Rubbo B, Best S, Hirst RA, et al. Clinical features and management of children with primary ciliary dyskinesia in England. Arch Dis Child 2020; 105: 724-729.

9 Pedersen ESL, Collaud ENR, Mozun R, et al. COVID-PCD: a participatory research study on the impact of COVID-19 in people with primary ciliary dyskinesia. ERJ Open Res 2021; 7: 00843-2020.

10 Goutaki M, Papon J-F, Boon M, et al. Standardised clinical data from patients with primary ciliary dyskinesia: FOLLOW-PCD. ERJ Open Res 2020; 6: 00237-2019.

11 John Hopkins Coronavirus Resource Centre Cumulative Cases. 2020. https://coronavirus.jhu.edu/data/ cumulative-cases Date last accessed: 29 January 2021.

12 Swiss Federal Office of Public Health. Coronavirus: Situation in Switzerland. 2021. www.bag.admin.ch/bag/en/ home/krankheiten/ausbrueche-epidemien-pandemien/aktuelle-ausbrueche-epidemien/novel-cov/ situation-schweiz-und-international.html Date last accessed: 10 Feburary 2021. Date last updated: 10 February 2021.

13 Syangtan G, Bista S, Dawadi P, et al. Asymptomatic SARS-CoV-2 carriers: a systematic review and meta-analysis. Front Public Health 2021; 8: 587374.

14 Corvol H, de Miranda S, Lemonnier L, et al. First wave of COVID-19 in French patients with cystic fibrosis. J Clin Med 2020; 9: 3624. 